\title{
Comparison of Indonesian Growth Reference Chart and World Health Organization Child Growth Standard in Detecting Stunting: A Systematic Review and Meta-analysis of 15,874 Children
}

\author{
(D) Gilbert Sterling Octavius, (1) Chelsea Serena br. Pardede, (D) Cindy Clarissa Thandy, (D) Clauvinna Adhityana Lie Fisca, \\ (D) Andry Juliansen
}

Universitas Pelita Harapan Faculty of Medicine, Department of Pediatrics, Banten, Indonesia

\begin{abstract}
What is already known on this topic?
The World Health Organization Child Growth Standards (WHOCGS) overestimates the stunting population in several countries, including Indonesia. An accurate growth standard is needed to avoid overdiagnosis and overtreatment of stunting.
\end{abstract}

What this study adds?

This systematic review and meta-analysis combine the previous findings that compare WHOCGS and the 2018 Indonesian Growth Reference Chart (IGRC). Pooled analysis showed that the IGRC resulted in a lower prevalence of stunted and severely stunted but not normal and tall children.

\begin{abstract}
Recognition of an overestimation of stunted children in Indonesia when using the World Health Organization Child Growth Standards (WHOCGS) led to the creation of the Indonesian Growth Reference Chart (IGRC) in 2005, with further improvement in 2018. This systematic review aimed to determine whether there is a difference in the diagnosis of stunting when using these two charts. This systematic review is registered in the PROSPERO database (CRD42021259934). Literature research was performed on PubMed, Science Direct, Medline, Scielo, Medrxiv, Research Square, SSRN, and Biorxiv to identify studies published from 2018 onwards that examined the comparison of IGRC and WHOCGS in detecting stunting. Three studies were included in this review. Pooled analysis showed that IGRC resulted in a lower prevalence of stunted and severely stunted children [risk ratio (RR): 0.28 ( $95 \%$ confidence intervals (CI): 0.15 $0.51), p<0.0001, I^{2}=97 \%$ ]. Comparison between IGRC and WHOGCS for prevalence of normal height children showed that there was no difference, and this finding was not significant [RR: 1.56 (95\% CI: 0.92-2.66), $\mathrm{p}=0.1, \mathrm{I}^{2}=100 \%$ ], and the comparison for prevalence of tall children also showed that there was no difference when using IGRC or WHOGCS, and this finding was also insignificant [RR: 2.02 (95\% CI: 0.78-5.20), $\mathrm{p}=0.14, \mathrm{I}^{2}=98 \%$ ]. This meta-analysis showed that stunted and severely stunted Indonesian children are over-represented using WHOCGS. The difference between IGRC and WHOCGS has occurred because of the sample population, as IGRC includes children from all 33 provinces in Indonesia, better reflecting the growth of all children in Indonesia.
\end{abstract}

Keywords: Indonesian Growth Reference Chart, WHO Growth Chart, stunting

\section{Introduction}

Despite improvements in accessibility to basic needs, such as food and water and primary medical care, stunting is still prevalent amongst Indonesian children (1). Although the percentage of children with stunting decreased to $11.6 \%$ in 2020 , some provinces still have more than $20 \%$ of children who suffer from stunting (2).
It was previously believed that undernutrition was the leading cause of stunting (3), so aggressive nutrition has been provided for stunted children, which resulted in increased prevalence of obesity (4). Starvation inhibits growth, but intervention at a nutritional level does not show any beneficial effect (3). Similarly to other countries that have adopted local reference growth charts, an
Address for Correspondence: Gilbert Sterling Octavius MD, Universitas Pelita Harapan Faculty of Medicine, Department of Pediatrics, Banten, Indonesia

Phone: +6221 54210130 E-mail: sterlinggilbert613@hotmail.com ORCID: orcid.org/0000-0002-6439-6265

${ }^{\circ}$ Copyright 2022 by Turkish Pediatric Endocrinology and Diabetes Society

The Journal of Clinical Research in Pediatric Endocrinology published by Galenos Publishing House.
Conflict of interest: None declared Received: 19.08 .2021 Accepted: 06.11.2021 
overestimation of stunted children in Indonesia was noted when using the World Health Organization Child Growth Standards (WHOCGS) (5). Some other factors may influence the potential growth of South East Asian children, such as variation in genetic growth potential and intergenerational epigenetic growth limitations (6). When investigating stunted and stunting children, other anthropometric measurements, such as body mass index (BMI), skinfold thickness, or even height standard deviation scores, need to be considered. This is because one or more obvious clinical symptoms of malnutrition are present in stunted children (3).

Therefore, an Indonesian Growth Reference Chart (IGRC) was created in 2005 (7) and was further improved in 2018 (8). However, the adoption of IGRC is still slow, even though there are apparent disparities between findings using WHOCGS and IGRC $(7,8)$. Therefore, the primary aim of this systematic review was to determine whether there is a difference in diagnosis of stunting when using these two charts (2006 WHOCGS vs 2018 IGRC). The secondary aim was to assess whether IGRC charts also detect normal height children and tall children better than WHOGCS.

\section{Methods}

\section{Eligibility Criteria}

The Preferred Reporting Items for Systematic Review and Meta-Analysis (PRISMA) 2020 statement was followed in this systematic review $(9,10)$. The protocol for this systematic review has been uploaded to the International Prospective Register of Systematic Reviews (PROSPERO) database (CRD42021259934).

The literature search was limited to the period from 2018 onwards, with no restrictions on language. The reason for the timeframe restriction was because the version of IGRC used in this study was published in 2018 (8). All cross-sectional studies and cohort studies were eligible for inclusion in this review. The inclusion criteria were children aged 0-60 months with their height measured and plotted against both IGRC and WHOCGS. Exclusion criteria comprised studies making comparison of stunting using charts other than the specific two in question - IGRC and WHOCGS. Abstracts, letters to the editor, and reviews were screened for references to ensure literature saturation before they were excluded.

Stunting was defined as length/height below -2 standard deviation (SD) for children under the age of two, while severe stunting was defined as length/height below -3 SD for children under the age of three for both WHOCGS and IGRC, taking into account their sexes.

\section{Search Strategy and Study Selection}

The literature search started on July 10, 2021, and ended on the same day. The authors utilized four public databases, PubMed, Science Direct, Medline, and Scielo, and four different preprint databases, Medrxiv, Research Square, SSRN, and Biorxiv. Table 1 contains a list of keywords used to search each database.

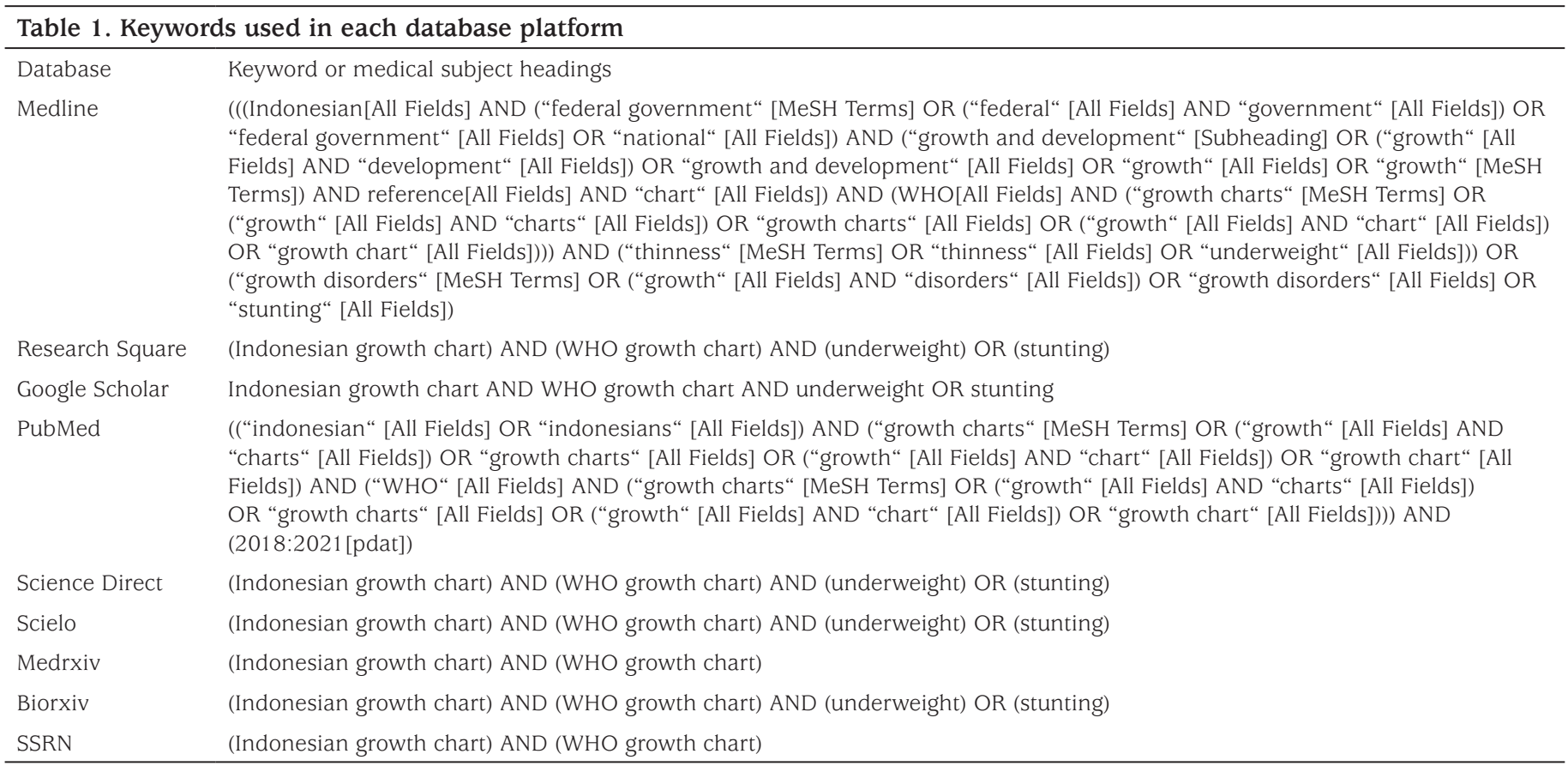




\section{Data Extraction and Quality Assessment}

Three independent reviewers ( $\mathrm{CP}, \mathrm{CT}$, and $\mathrm{CF}$ ) compiled the data in a standardized format, including demographic characteristics of the included participants (age, sex, and height) and prevalence of stunting according to IGRC and WHOCGS. It was planned that if there was any missing data needed for this systematic review in any identified study, the corresponding author of the research would be contacted directly.

The same independent reviewers conducted the quality assessment of each study. The Newcastle Ottawa Quality Assessment Scale (NOS) was used to assess the quality of cross-sectional and longitudinal studies (11). Any differences between NOS results were discussed until a consensus was reached. If there were still any unresolved disagreements, two expert reviewers (GSO and AJ) were consulted, and the final decision was made based on their expertise and consensus. A score of $\geq 7$ was the cut-off used for a study to be considered of good quality (11).

\section{Statistical Analysis}

The meta-analysis was carried out using the Review Manager 5.4 (Cochrane Collaboration) software. The risk ratios (RR) and their 95 percent confidence intervals (CI) were calculated using Mantel-Haenszel's formula. In contrast, the mean difference and its SD were calculated using the Inverse Variance technique. Low, moderate, and high degrees of heterogeneity was determined using the $\mathrm{I}^{2}$ statistic, with values of 25 percent, 26 percent -50 percent, and $>50$ percent, respectively. When the two-tailed p-value was 0.05 or less, the results were considered significant. Begg's funnel plot analysis was used to estimate the qualitative risk of publication bias.

\section{Results}

The study selection process is listed in Figure 1, where ultimately, three studies were selected for inclusion in this review $(12,13,14)$. Two studies $(12,13)$ had good quality with a NOS of eight each, while Hilmy and Fatharani's (14) (2021) study only scored five using NOS (Table 2). All of the studies were cross-sectional studies. There were 15,874 children included in total in this review, with 7372 children being male $(46.4 \%)$. Using WHOCGS, there were 7627 stunted children $(48.04 \%)$, while there were only 1884 stunted children $(11.87 \%)$ when plotted against the IGRC.

Three studies $(n=15,874)$ reported on the prevalence of stunted and severely stunted children. Pooled analysis showed that IGRC resulted in a lower prevalence of stunted and severely stunted children [RR: 0.28 (95\% CI: 0.15 -
0.51), $\quad \mathrm{p}<0.0001, \quad \mathrm{I}^{2}=97 \%$, random-effect modelling; Figure 2A]. When comparing IGRC and WHOGCS in terms of normal height children, pooled analysis of the three studies ( $n=15,874)$ showed that there was no difference, and this finding was not significant 'RR 1.56 (95\% CI: 0.922.66), $p=0.1, I^{2}=100 \%$, random-effect modelling; Figure 2B]. Lastly, pooled analysis of tall children from two studies $(n=15,656)$ showed that there was also no difference between IGRC and WHOGCS, and this finding was also insignificant [RR: $2.02(95 \%$ CI: 0.78-5.20), $p=0.14$, $\mathrm{I}^{2}=98 \%$, random-effect modelling; Figure $\left.2 \mathrm{C}\right]$. The funnel plot was not used to visualize publication bias as there were less than ten studies (15).

\section{Discussion}

Several studies of the Indonesian population have attempted to identify factors associated with stunting in children $(16,17,18)$. However, there is little consensus on determinants that might be associated with stunting, prompting doctors, researchers, and government officials to discuss the potential of developing an IGRC. The need for a local growth reference chart stems from reports that

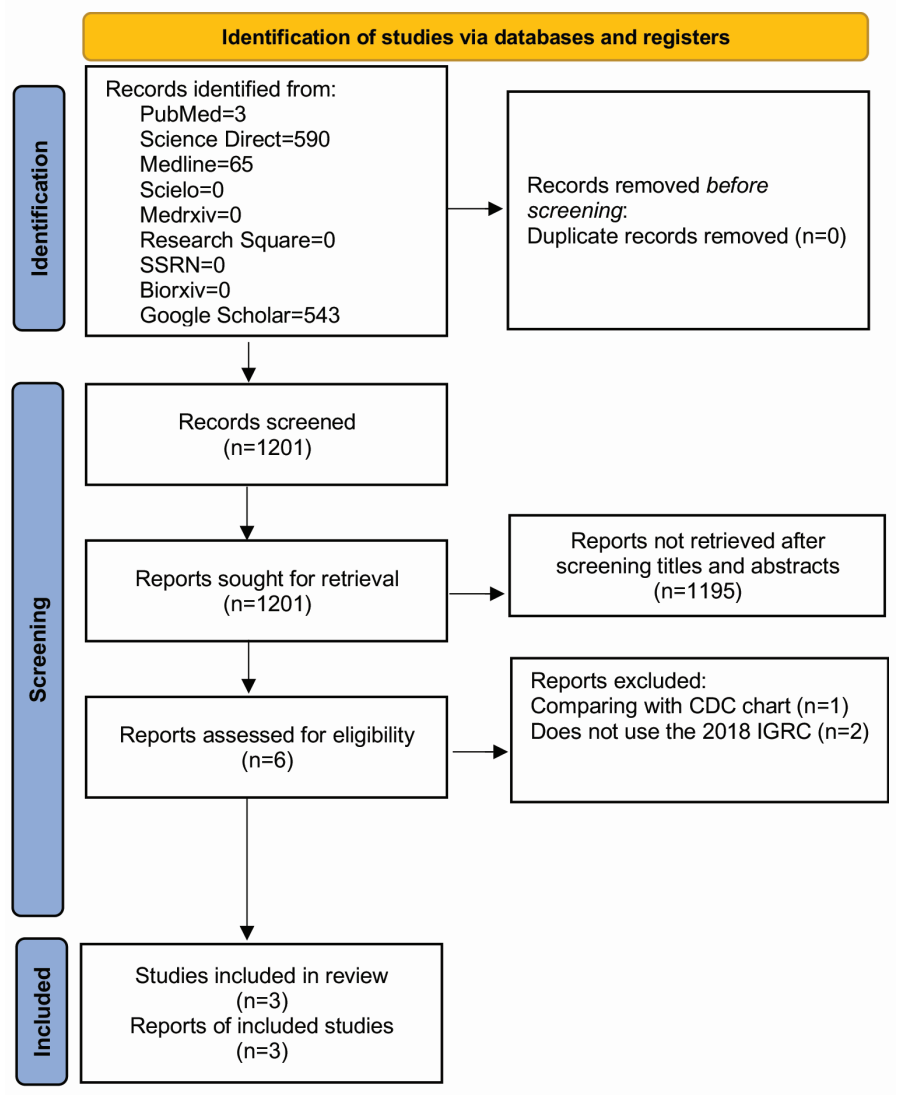

Figure 1. PRISMA flow chart of this study

IGRC: Indonesian Growth Reference Chart 
WHOCGS is more likely to overdiagnose underweight and stunting in otherwise normal children (19). The result of this meta-analysis supports this finding, as stunted and severely stunted were over-represented when using the WHOCGS in the three studies examined. The main difference between
IGRC and WHOCGS is in the sample population. While WHOCGS includes children that have followed the feeding recommendations of the WHO, IGRC includes children from all 33 provinces in Indonesia which better reflects the growth of children in the whole population of Indonesia

\begin{tabular}{|c|c|c|c|c|c|c|c|c|}
\hline \multirow[t]{2}{*}{ Author (year) } & \multirow[t]{2}{*}{ Study location } & \multirow{2}{*}{$\begin{array}{l}\text { Total sample } \\
\text { (\% male) }\end{array}$} & \multirow{2}{*}{$\begin{array}{l}\text { Stunted } \\
\text { children } \\
\text { according } \\
\text { to } \\
\text { WHOCGS } \\
(\%) \\
\end{array}$} & \multirow{2}{*}{$\begin{array}{l}\text { Stunted } \\
\text { children } \\
\text { according } \\
\text { to IGRC } \\
(\%)\end{array}$} & \multirow[t]{2}{*}{ Conclusion } & \multicolumn{3}{|c|}{ NOS } \\
\hline & & & & & & Selection & Comparability & Outcome \\
\hline Novina et al (12) & Bandung & $12772(54.6)$ & $\begin{array}{l}7193 \\
(56.31)\end{array}$ & $\begin{array}{l}1698 \\
(13.3)\end{array}$ & $\begin{array}{l}\text { The WHOCGS grossly } \\
\text { underestimates the } \\
\text { true prevalence of } \\
\text { malnourishment among } \\
\text { Indonesian children. }\end{array}$ & 4 & 1 & 3 \\
\hline Flynn et al (13) & $\begin{array}{l}\text { Musi sub- } \\
\text { district }\end{array}$ & $218(49.5)$ & $112(51.4)$ & $18(8.3)$ & $\begin{array}{l}\text { In Musi sub-district, } \\
\text { WHOCGS is not } \\
\text { appropriate for } \\
\text { reflecting child growth. }\end{array}$ & 3 & 2 & 3 \\
\hline
\end{tabular}

A)

\begin{tabular}{|c|c|c|c|c|c|c|}
\hline \multirow[b]{2}{*}{ Study or Subgroup } & \multicolumn{2}{|c|}{ IGRC } & \multicolumn{2}{|c|}{ WHOCGS } & \multirow[b]{2}{*}{ Weight } & $\mathbf{R}$ \\
\hline & Events & Total & Events & Total & & M-H, \\
\hline Flynn 2020 & 18 & 218 & 112 & 218 & $29.7 \%$ & \\
\hline Hilmy 2021 & 168 & 2884 & 322 & 2884 & $34.7 \%$ & \\
\hline Novina 2020 & 1698 & 12772 & 7139 & 12772 & $35.6 \%$ & \\
\hline Total $(95 \% \mathrm{Cl})$ & & 15874 & & 15874 & $100.0 \%$ & \\
\hline Total events & 1884 & & 7573 & & & \\
\hline
\end{tabular}

Risk Ratio Risk Ratio

, Random, 95\% Cl

$0.16[0.10,0.25]$

$0.52[0.44,0.62]$

$0.24[0.23,0.25]$

$0.28[0.15,0.51]$

Test for overall effect: $Z=4.09(P<0.0001)$

B)

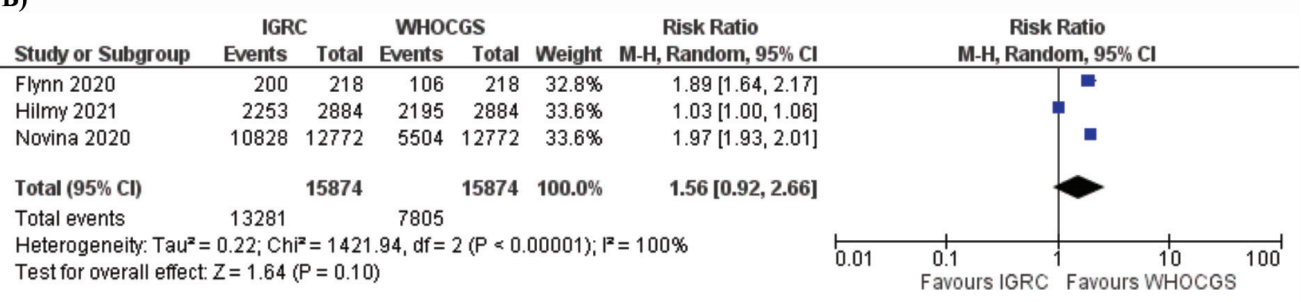

C)

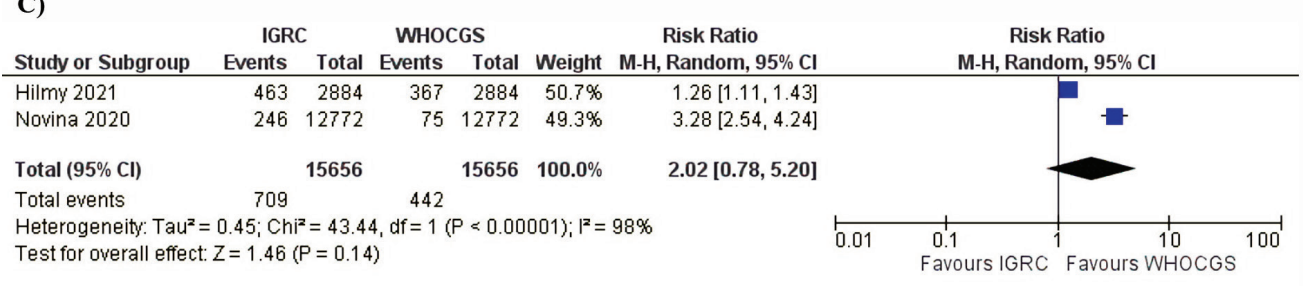

Figure 2. Forest plot that demonstrates the association of stunting and severe stunting (A), normal height (B), and tall (C) children when comparing IGRC and WHOCGS

WHOCGS: World Health Organization Child Growth Standard, IGRC: Indonesian Growth Reference Chart, CI: confidence interval 
(13). Genetic and unknown environmental factors are still debated as the cause of differences between local growth reference charts and WHOCGS population analyses (20).

\section{Study Limitations}

However, a local growth reference chart also has limitations, including both statistical and practical limitations (20). This might explain why there are no differences in IGRC and WHOCGS in detecting normal height children and tall children. As the local guideline recommends using 2006 WHOCGS in children under five years old, we suggest that the IGRC can be incorporated when a child is stunted according to WHOCGS. If the child is clinically normal and the IGRC detects that the child is not stunted, these findings can be discussed and explained to the parents.

Several caveats should be noted when comparing WHOCGS and IGRC. While IGRC plots the development of 0-18 years old children, WHOCGS only plots for the 0-5 years old. Comparing IGRC and WHOCGS is thus like comparing apples with pears. The optimal growth chart, according to Karlberg's (21) infancy-childhood-puberty development model, should include the whole growth spectrum, from infancy to puberty, due to the significant variations in growth rates in each phase of childhood and WHOCGS does not do this.

There are several limitations of this review. Firstly, one study has a low NOS, which indicates that the study is not well-conducted and may have introduced a bias in our synthesis. Secondly, there are only three studies that could be included due to the limited number of studies available. There was one study that was excluded because the study used the 2005 IGRC instead of the 2018 IGRC (22). Lastly, there was significant heterogeneity amongst the studies that study design or publication bias might explain. However, despite the limitations, our meta-analysis might provide a stimulus for clinicians, researchers, or government bodies to conduct more large, well-designed, prospective studies to investigate the continuous growth of children in terms of weight and height, in both Indonesia and other countries that have noted discrepant findings between WHOCGS and local growth reference charts.

\section{Conclusion}

The result of this meta-analysis showed that Indonesian stunted and severely stunted children are over-represented using WHOCGS compared to IGRC. This could be due to the difference in sample population between the two growth charts, because IGRC includes children from all 33 provinces in Indonesia. Despite this, IGRC also has its limitations which might explain why there are no differences in IGRC and WHOCGS in detecting the prevalence of normal height and tall children. Therefore, more well-designed, large, prospective studies are still needed to investigate this matter further.

\section{Ethics}

Ethics Committee Approval: Ethics is not required since this is a systematic review.

Informed Consent: Informed consent is not required since this is a systematic review.

Peer-review: Externally peer-reviewed.

\section{Authorship Contributions}

Concept: Gilbert Sterling Octavius, Andry Juliansen, Design: Gilbert Sterling Octavius, Chelsea Serena br. Pardede, Cindy Clarissa Thandy, Clauvinna Adhityana Lie Fisca, Andry Juliansen, Data Collection or Processing: Gilbert Sterling Octavius, Chelsea Serena br. Pardede, Cindy Clarissa Thandy, Clauvinna Adhityana Lie Fisca, Analysis or Interpretation: Gilbert Sterling Octavius, Andry Juliansen, Literature Search: Chelsea Serena br. Pardede, Cindy Clarissa Thandy, Clauvinna Adhityana Lie Fisca, Writing: Gilbert Sterling Octavius, Chelsea Serena br. Pardede, Cindy Clarissa Thandy, Clauvinna Adhityana Lie Fisca, Andry Juliansen.

Financial Disclosure: The authors declared that this study received no financial support.

\section{References}

1. United Nations Children's Fund. Nutrition Capacity Assessment in Indonesia: UNICEF;2018. Last Accessed Date: 2021 August 1. Available from: https://www.unicef.org/indonesia/media/1816/file/Nutrition \% 20 Assessment \% 202018.pdf

2. Kementerian Kesehatan Republik Indonesia. Laporan Kinerja Kementerian Kesehatan Tahun 2020: Kementerian Kesehatan Republik Indonesia;2021. Last Accessed Date: 2021 August 1. Available from: http://ppid.kemkes.go.id/uploads/img_60e3c13edba9f.pdf

3. Scheffler C, Hermanussen M, Bogin B, Liana DS, Taolin F, Cempaka PMVP, Irawan M, Ibbibah LF, Mappapa NK, Payong MKE, Homalessy AV, Takalapeta A, Apriyanti S, Manoeroe MG, Dupe FR, Ratri RRK, Touw SY, K PV, Murtani BJ, Nunuhitu R, Puspitasari R, Riandra IK, Liwan AS, Amandari P, Permatasari AAI, Julia M, Batubara J, Pulungan A. Stunting is not a synonym of malnutrition. Eur J Clin Nutr 2020;74:377-386. Epub 2019 May 29

4. Julia M, van Weissenbruch MM, Prawirohartono EP, Surjono A, Delemarre-van de Waal HA. Tracking for underweight, overweight and obesity from childhood to adolescence: a 5-year follow-up study in urban Indonesian children. Horm Res 2008;69:301-306. Epub 2008 Feb 6

5. Dwipoerwantoro PG, Mansyur M, Oswari H, Makrides M, Cleghorn G, Firmansyah A. Growth of Indonesian Infants Compared With World 
Health Organization Growth Standards. J Pediatr Gastroenterol Nutr 2015;61:248-252.

6. Hui LL, Schooling CM, Cowling BJ, Leung SS, Lam TH, Leung GM. Are universal standards for optimal infant growth appropriate? Evidence from a Hong Kong Chinese birth cohort. Arch Dis Child 2008;93:561565. Epub 2007 Jun 7

7. Batubara J, Alisjahbana A, Gerver-Jansen A, Alisjahbana B, Sadjimin T, Tasli Y, Juhariah J, Tririni A, Padmosiwi WI, Listiaty T, van de Waal YT, van De Waal HAD, Gevrer WJ. Growth diagrams of Indonesian children The nationwide survey of 2005. Paediatrica Indonesiana 2006;46:118126.

8. Pulungan $A B$, Julia $M$, Batubara JRL, Hermanussen M. Indonesian National Synthetic Growth Charts. Acta Scientific Paediatrics 201 8;1:2034

9. Page MJ, McKenzie JE, Bossuyt PM, Boutron I, Hoffmann TC, Mulrow CD, Shamseer L, Tetzlaff JM, Akl EA, Brennan SE, Chou R, Glanville J, Grimshaw JM, Hróbjartsson A, Lalu MM, Li T, Loder EW, Mayo-Wilson E, McDonald S, McGuinness LA, Stewart LA, Thomas J, Tricco AC, Welch VA, Whiting P, Moher D. The PRISMA 2020 statement: an updated guideline for reporting systematic reviews. Syst Rev 2021;10:89.

10. Rethlefsen ML, Kirtley S, Waffenschmidt S, Ayala AP, Moher D, Page MJ, Koffel JB; PRISMA-S Group. PRISMA-S: an extension to the PRISMA Statement for Reporting Literature Searches in Systematic Reviews. Syst Rev 2021;10:39.

11. Wells G, Shea B, O’Connell D, Peterson J, Welch, Losos M, Tugwell P. The Newcastle-Ottawa Scale (NOS) for Assessing the Quality of Nonrandomised Studies in Meta-Analyses. 2014. Available from: http:// www.ohri.ca/programs/clinical_epidemiology/oxford.asp

12. Novina N, Hermanussen M, Scheffler C, Pulungan AB, Ismiarto YD, Andriyana Y, Biben V, Setiabudiawan B. Indonesian National Growth Reference Charts Better Reflect Height and Weight of Children in West Java, Indonesia, than WHO Child Growth Standards. J Clin Res Pediatr Endocrinol 2020;12:410-419. Epub 2020 Aug 10

13. Flynn J, Alkaff FF, Sukmajaya WP, Salamah S. Comparison of WHO growth standard and national Indonesian growth reference in determining prevalence and determinants of stunting and underweight in children under five: a cross-sectional study from Musi sub-district. F1000Res 2020;9:324.

14. Hilmy N, Fatharani M. Prevalence of Stunting to WHO Growth Standards and Indonesian Growth Reference Charts: A Descriptive Study from Blega Sub-District. Journal of Agromedicine and Medical Sciences 2021;7:98-103.

15. Thornton A, Lee P. Publication bias in meta-analysis: its causes and consequences. J Clin Epidemiol 2000;53:207-216.

16. Beal T, Tumilowicz A, Sutrisna A, Izwardy D, Neufeld LM. A review of child stunting determinants in Indonesia. Matern Child Nutr 2018;14:e12617. Epub 2018 May 17

17. De Silva I, Sumarto S. Child Malnutrition in Indonesia: Can Education, Sanitation and Healthcare Augment the Role of Income? Journal of International Development 2018;30:837-864.

18. Titaley CR, Ariawan I, Hapsari D, Muasyaroh A, Dibley MJ. Determinants of the Stunting of Children Under Two Years Old in Indonesia: A Multilevel Analysis of the 2013 Indonesia Basic Health Survey. Nutrients 2019;11:1106.

19. Hermanussen M, Stec K, Aßmann C, Meigen C, Van Buuren S. Synthetic growth reference charts. Am J Hum Biol 2016;28:98-111. Epub 2015 Jun 30

20. Milani S, Buckler JM, Kelnar CJ, Benso L, Gilli G, Nicoletti I, Faglia G, Radetti G, Bona G, Schonbeck Y, Van Buuren S, Hermanussen M, Grugni G, Marazzi N, Júlíusson PB, Roelants M, Hoppenbrouwers K, Hauspie R, Bjerknes R, Lejarraga H, Sartorio A. The use of local reference growth charts for clinical use or a universal standard: a balanced appraisal. J Endocrinol Invest 2012;35:224-226.

21. Karlberg J. Secular trends in pubertal development. Horm Res 2002;57(Suppl 2):19-30.

22. Wicaksono RA, Aroto KS, Saragih RAK, Deliana M, Lubis M, Batubara JRL. Comparison of Growth Diagrams of Indonesian Children to 2006 World Health Organization Growth Standards in Diagnosing Stunting. Paediatrica Indonesiana 2020;60:95-100. 